\title{
Práticas de leitura de literatura no ensino de ELE para os anos iniciais do Ensino Fundamental I
}

\author{
Literature reading practices in the scope of Spanish as a foreign language teaching for the \\ first years of Basic Education
}

\author{
Leila Shaí Del Pozo González \\ Universidade Estadual do Oeste do Paraná (UNIOESTE) \\ Cascavel, Paraná, Brasil
}

Resumo: O estudo introduz algumas reflexões sobre como abordar as literaturas na aula de espanhol como língua estrangeira (ELE) e discute sobre o que deveria de ser considerado como texto literário. Também, defende o tema do uso da literatura latino-americana nas escolas propondo que seja utilizada nas aulas de língua (tanto materna como estrangeira) como componente importante para a formação dos alunos e que seja feita sua leitura crítica e discussão em sala ao lado das literaturas do cânone. No final, o artigo oferece uma proposta de aplicação de literatura em sala de ELE com base em textos do gênero literário nonsense. Dessa forma, objetiva contribuir ao leque de possibilidades de planejamento para a aula de ELE com o uso de textos literários.

Palavras-chave: Literatura na aula de ELE; Concepções e práticas literárias; Literatura em aulas língua da educação básica.

\begin{abstract}
The study introduces some thoughts on how to approach literature in the scope of Spanish language teaching. In addition, it exhibits some theoretical discussions about what makes a text to be qualified as literary. Likewise, it sustains the use of Latin American literature at school in the scope of (native and foreign) language teaching as an important component of a student's education. Moreover, it suggests reading texts of the Latin American literature in classes with critical discussions together with those of the literary canon. The article ends with a proposal of a literature teaching approach in the scope of Spanish language teaching with the use of the nonsense literature. This way, this article aims to contribute to the range of possibilities on lesson planning for Spanish as a foreign language classes with the use of literary texts.
\end{abstract}

Keywords: Literature in the scope of Spanish language teaching; Concepts and literary practices; Literature in the Basic Education language classes.

\section{INTRODUÇÃO}

O ensino da língua espanhola, infelizmente, ainda é abordado como o ensino das estruturas linguísticas apenas. Esse emprego não está atrelado, exclusivamente, ao ensino/aprendizagem dessa língua, pois também pode-se observar processos similares

\footnotetext{
*Mestre pelo programa de pós-graduação em Letras - UNIOESTE. Doutoranda do mesmo programa de pós-graduação em Letras. Professora colaboradora da área de letras espanhol na UNIOESTE/Cascavel. Email: leilashai@hotmail.com.
} 
nas aulas de outros idiomas e, inclusive, no ensino da nossa língua materna nas escolas. Aparentemente, a literatura é evitada por ser considerada como um objeto precioso, tão inestimável, que faz-se preferível evita-la, ou, ainda, como algo difícil, quase inalcançável para os alunos. Acredita-se que está sempre desligada dos conteúdos que "precisam ser estudados" nas aulas de língua.

Enquanto isso, ao longo da formação docente, o formando não aprende sobre a necessidade e importância da literatura nas aulas de língua (materna ou estrangeira). Este olhar resulta em que uma vez já formado o docente não dê espaço à literatura no seu planejamento de aulas, pois a literatura se tornou um desafio muito grande para o professor, que também não lê e não estuda. E, se existem aulas com textos literários, estes são abordados desconsiderando a sua literariedade, já que, como mencionam Fleck e Zucki (2015, p. 143):

Os professores, muitas vezes, deixam de aplicar técnicas e estratégias adequadas à aprendizagem por não as conhecerem e, por consequência, não conseguem dinamizar ou dar um bom direcionamento às aulas de leitura literária. Portanto, ou ministram aulas de literatura com pouco conhecimento acerca das teorias necessárias ou fazem dessa leitura algo distante da literatura.

Talvez nós docentes devamos nos aprofundar mais nesse assunto e verificar qual é a nossa postura diante disso e, se for o caso, deveríamos refletir sobre a abordagem que adotamos enquanto ao ensino das literaturas na aula de línguas. O presente artigo vem ao encontro das questões do uso da literatura nas aulas de espanhol como língua estrangeira (ELE), pergunta-se sobre o que deveria ser considerado texto literário e reflete sobre o uso das produções literárias, com ênfase na literatura latino-americana, nas aulas de ELE, apresentando ao final esboços para uma proposta de aplicação em sala de ELE, a partir de textos da literatura nonsense.

\section{QUE LITERATURA ENSINAR NAS AULAS DE LÍNGUA?}

Com respeito ao ensino/aprendizagem das literaturas, observa-se que se dá preferência a livros considerados como 'maiores' - se não forem de autores europeus ou estadunidenses, ou, em tratando-se dos nacionais, dos consagrados, que "a obra pelo menos precisa" ter sido considerada dentro da lista de livros exigidos como quesito básico para o aluno ser aprovado no vestibular.

Nesse âmbito, do mesmo modo, está presente o raciocínio de que a literatura tira o espaço de assuntos mais importantes e, como resultado, quase não se incentiva a leitura da literatura em geral. Assim, a literatura passa a ser abordada exclusivamente em turmas que pretendem iniciar o treinamento para o vestibular, com o objetivo de os vestibulandos não zerarem nas questões obrigatórias de literatura daquela prova. Enquanto que nas outras turmas, se existe uma hora destinada para a leitura, nem sempre é possível observar 
um trabalho que realmente permita afirmar: eles (nossos alunos) estão lendo literatura. A respeito deste último aspecto, Raymond Williams (1979) e Terry Eagleton (2003) discorrem sobre a problemática que o termo literatura apresenta em si.

Dentre os assuntos analisados por Williams, podemos mencionar que o conceito moderno de literatura não teria surgido antes do século XVIII, consolidando-se plenamente como tal no século XIX, tendo como significado "uma situação de leitura: ser capaz de ler e ter lido" (WILLIAMS, 1979, p. 51), na sua raiz em latim littera, letra, isto é, literatura somente seria a produção escrita.

Portanto, seguindo o apontado por Williams (1979), com respeito às produções orais, hoje precisamos refletir sobre a questão que remete ao caso do conceito de literatura adotado por nós desconsiderar a literatura oral, por exemplo a dos povos autóctones, latino-americanos ou de a de outras partes do mundo - como, por exemplo, a Iliada e a Odisseia (ABREU, 2006) - ou se obras tais como Hamlet, de Shakespeare, ou, o Dom Quixote de la Mancha, de Cervantes deixariam de ser literatura por ser anteriores ao conceito moderno já que foram escritos antes do século XVIII. Acreditamos que esse não seria o caso, assim sendo, igualmente, todas as literaturas orais devem ser consideradas.

Eagleton (2003, p. 6, aspas simples do autor), por seu lado, afirma que - e nós observamos nos dias atuais na fala de muitos professores - ainda se aplica o conceito elaborado pelos formalistas russos que: "consideravam a linguagem literária como um conjunto de desvios da norma, uma espécie de violência linguística: a literatura é uma forma 'especial' de linguagem, em contraste com a linguagem 'comum', que usamos habitualmente.", e que, sendo assim, a literatura teria que ser uma linguagem incomum, diferente. Portanto, teríamos que desconsiderar a possibilidade de mimese da realidade em uma obra que utiliza uma linguagem simples, clara e do cotidiano. Essa prática seria um erro.

Márcia Abreu (2006), além dos assuntos mencionados nos parágrafos acima, comenta sobre o que faz um texto ser qualificado como "literário". Desse modo, a autora mostra que tanto o "erudito" quanto o "popular" devem ser considerados dentro dos estudos da literatura em sala - e nós podemos fazer isso nas aulas de língua -. A autora traz como exemplo de produção literária "popular" o caso dos poetas nordestinos Zé Pretinho e Cego, cujas obras bem mereceriam estar dentro dessa lista da chamada literatura com maiúscula. Como a estudiosa expõe, geralmente, "para que uma obra seja considerada Grande Literatura, ela precisa ser declarada literária pelas chamadas 'instâncias de legitimação"' (ABREU, 2006, p. 40, aspas simples da autora), que seriam: a universidade, a mídia, os livros didáticos, os estudos críticos de obras literárias, etc.

Desse modo, a mudança desses conceitos sobre o que seria literatura, a literariedade das obras, a nossa apertura diante de obras que não se encontram no cânone ditatorial literário, entre outros, deve ser feita já nas nossas práticas. Ao mesmo tempo, de acordo com Abreu (2006, p. 107, itálicos da autora): "Os critérios de avaliação do que é boa e má literatura, e até mesmo de que gêneros são considerados literários, mudam com o tempo. Não há uma literariedade intrínseca aos textos nem critérios de avaliação atemporais." Portanto, nesse sentido, não podemos esquecer de nosso papel, como acadêmicos, de discutir e achar formas, ou soluções, que possam contribuir na mudança do panorama 
atual de nosso entendimento de porquê e o quê ensinar da literatura e, também, o como se faz. Desse modo, o que deve nos preocupar seria ter como objetivo comparar as diferentes leituras, discuti-las com os alunos, mostrar seu funcionamento textual (ABREU, 2006) e sempre tentar aportar o melhor para o crescimento intelectual dos nossos alunos.

Assim, reutilizando as palavras de Abreu (2006), é alarmante que nas escolas não exista uma preocupação por ampliar em nossos alunos o conhecimento da própria cultura nem um interesse real pela cultura alheia, além de, em geral, desmerecer a nossa produção latino-americana. Talvez isto aconteça devido à forte marca que deixou a etapa colonizadora ao longo dos anos de formação da nossa identidade, já que em nós, colonizados, ao ser trazida a poderosa ferramenta da escrita alfabética, foi semeada a crença de que todo conhecimento anterior à vinda dos europeus seria sempre inferior. Dessa forma, sobre o processo educativo, como observa Paulo Freire (1985, p. [15]) devemos ter: "clareza em torno de a favor de quem e do quê, portanto contra quem e contra o quê, fazemos a educação e de a favor de quem e do quê, portanto contra quem e contra o quê."

Seguindo esta linha de pensamento, com respeito a nossas produções, consequentemente, ainda nós mesmos estaríamos caindo na ideia de sermos simples reprodutores do apreendido com as grandes metrópoles colonizadoras e que nunca conseguiríamos sair desse lugar menor (SANTIAGO, 2000). Consideramos que devido a que o nosso sistema educativo ainda ser pautado em modelos europeus (colonizadores/colonizantes), isto é, ao ignorar uma vasta produção maravilhosa latinoamericana, constata-se ainda a percepção de inferioridade e de dívida impagável aos nossos colonizadores.

Todavia, como Santiago (2000) expõe no seu ensaio "O entre-lugar do discurso latino-americano", há muito tempo que se observa nas produções latino-americanas uma assimilação antropofágica e insubordinada, que ao utilizar a ferramenta colonizadora (a escrita), faz-se evidente que o sistema literário 'emergente' já foi capaz, a partir de 1940, de superar e contribuir ao sistema literário universal, sem negar sua influência, tornandose independente e que, inclusive, atualmente, a Nova Narrativa Latino-americana, é a que mais produz a nível mundial. Os livros didáticos, em parte, ainda trazem essa percepção colonizadora com relação à literatura.

Sobre os nossos alunos, poder-se-ia afirmar que, ultimamente, estão lendo. Este acontecimento, porém, não é uma notícia muito tranquilizadora, pois trata-se de livros, em sua maioria, traduzidos de outras línguas. Nada contra esses livros, que são muito bons, porém é necessário observar, também, que, em geral, não se faz nenhum tipo de análise destes, ou discussão com os alunos sobre o tipo de ideologia transmitida neles e como, sem percebermos, damos, às vezes, a entender que ler a nossa produção nacional/latino-americana é enfadonha, além de inferior, parece não ser "tão legal" quanto a estrangeira. Não buscamos, desse modo, proibir ou desmerecer a leitura da literatura estrangeira nas escolas, pois nossos alunos devem estudá-la e conhecê-la muito bem para aprimorar a sua formação, mas o dilema é outro: existem ainda muitos setores nas sociedades colonizadas que cooperam com a manutenção do colonialismo e, não 
conhecer a própria cultura e a própria história, é um estado alienado e este é um dos resultados mais eficientes desse sistema que ainda persiste em muitos setores da América Latina.

Devemos repensar sobre que as obras literárias: "não existem unicamente como realidades estéticas. Elas são também objetos de linguagem que - pelo fato de exprimirem uma cultura, um pensamento e uma relação com o mundo - merecem que nos interessemos por elas [...]" (JOUVE, 2012, p. 135, itálicos nossos). Assim, ao não ofertar ou discutir leituras da nossa literatura latino-americana, estamos deixando a leitura de aspectos essenciais de nossa cultura, o cultivo de nossos pensamentos e as premissas de nossas relações com o mundo, deixamos de lado os vínculos necessários com a nossa realidade latino-americana para o assentamento de uma identidade própria, mestiça, híbrida, sincrética e plural.

De acordo com Freire (1987, p. 40): “o educador problematizador refaz, constantemente, seu ato cognoscente, na cognoscibilidade dos educandos. Estes, em lugar de serem recipientes dóceis de depósitos, são agora investigadores críticos, em diálogo com o educador, investigador crítico, também." É desse modo que nós somos responsáveis pela formação de leitores conscientes no espaço escolar. As obras veiculam, conforme expressa Jouve (2012), na citação anteriormente mencionada, em "um pensamento e uma relação com o mundo". Daí nossas questões: que cultura? Que pensamento? E que relação com o mundo está entretecida nas obras que os nossos alunos leem na escola?

\section{A LITERATURA E A FORMAÇÃO DO ALUNO LATINO-AMERICANO}

Marta Sanz Pastor (2006) afirma que é possível um medo inicial do professor, e dos aprendizes, ao sair do seu lugar de conforto. Assim, talvez, possa haver o predomínio de uma atitude de rejeição da literatura em sala de aula, já que nem todos fazem parte desse grupo que desfruta da leitura de literatura. Porém, é necessário ir além dos conteúdos de língua, pois nossos objetivos, como professores, incluem preparar de maneira efetiva nossos alunos (de língua materna e estrangeira). No caso da literatura, tal qual Sanz Pastor aponta, seu ensino se justifica pelo fator de ser instrumentalização intercultural e a possibilidade de preparar de uma forma mais completa o aluno para o mundo globalizado em que vivemos.

Em confluencia com Sanz Pastor, Mendoza Fillola (2008, p. 5) declara que: “[...] cuando se toma como material de aula, el texto literario suscita que se produqca el aprendizaje a través de la interrelación de saberes, de conocimientos, de vivencias culturales y de la integración en los distintos bloques de saberes que componen la competencia lingüistica y literaria ${ }^{1}$." Logo, observamos que ter a literatura na aula de língua estrangeira nos oportuniza a aproveitar a obra além de simples questões gramaticais, de vocabulário, de interpretação textual, da prática da pronúncia dos vocábulos em língua estrangeira, de exemplos de língua que podem ser dissecadas e

\footnotetext{
${ }^{1}$ Nossa tradução: [...] quando se toma como material de aula, o texto literário suscita que se produza a aprendizagem através da inter-relação de saberes, de conhecimentos, de vivências culturais e da integração nos distintos blocos de saberes que compõem a competência linguística e literária.
} 
examinadas, entre outras "teorias e práticas antigas" (MENDOZA FILLOLA, 2008) que geralmente são aplicadas aos textos.

Segundo Mendoza Fillola (2008), o texto literário exibe ao aluno leitor as convenções com que se usa a língua estrangeira que está aprendendo, resultando em que possa aprender, entender e saber fazer uso pertinente do seu conhecimento socio-cultural aprendido, além de oportunizar:

[...] una compleja actividad cognitiva de construcción de significados y de atribución de interpretaciones, de reconocimiento de elementos, de formas, de relaciones y de usos lingüísticos y también de atribución de valores expresivos; [entre otros]; [...] A modo de síntesis [...] puede señalarse que cada acto de lectura hace que el lector aprendiz formule anticipaciones sobre el contenido, el significado y, también, sobre aspectos gramaticales, funcionales y de uso. Acertadamente ha puntualizado G. Lazar la importancia formativa de las conexiones que hay entre las hipótesis y las inferencias de orden lingǘstico que elabora y establece el aprendiz de LE (Lengua Extranjera) y las muestras discursivas que surgen del mismo discurso literario en el proceso de aprendizaje. ${ }^{2}$ (MENDOZA FILLOLA, 2008, p. 12).

Dessa forma, vários são os aspectos a serem considerados quando estudamos a produção literária nacional e latino-americana. Por outro lado, para Candido (2004) ensinar literatura seria uma questão de direito. Para o autor, todos deveriam ter acesso à literatura, pois esta ajuda a transformar o leitor num cidadão empaticamente ciente da presença do outro, humanizando-o. Em palavras de Sanz Pastor (2006, p. 350), com a literatura, não somente é possível a construção da competência plurilíngue e pluricultural, mas além disso, trata-se de uma competência que: "compendia los saberes y destrezas que debe poseer ese estudiante de lenguas que aspira a ser, a la vez, agente social, mediador interculturaly aprendiz. autónomo."

De acordo com a leitura que faz Fleck (2015, p. 169, Monserrat Espinet (1999),

[...] a abordagem da cultura é um dos aspectos mais úteis na motivação dos estudantes de língua estrangeira, já que esta promove o desenvolvimento integral, a consciência da existência de uma identidade cultural própria, ao mesmo tempo em que amplia a visão do "outro" - a alteridade.

\footnotetext{
${ }^{2}$ Nossa tradução: [...] uma complexa atividade cognitiva de construção de significados e de atribuição de interpretações, de reconhecimento de elementos, de formas, de relações e de usos linguísticos e também de atribuição de valores expressivos; [entre outros]; [...] A modo de síntese [...] pode notar-se que cada ato de leitura faz com que o leitor aprendiz formule antecipações sobre o conteúdo, o significado e, também, sobre aspectos gramaticais, funcionais e de uso. Acertadamente apontou G. Lazar sobre a importância formativa das conexões que existem entre as hipóteses e as inferências de ordem linguística que elabora e estabelece o aprendiz de LE (Língua Estrangeira) e as mostras discursivas que surgem do mesmo discurso literário no processo de aprendizagem.

${ }^{3}$ Nossa tradução: compendia os saberes e as destrezas que deve possuir esse estudante de línguas que aspira a ser, por sua vez, agente social, mediador intercultural e aprendiz autônomo.
} 
Em confluência com Fleck (2015), expressamos que ensinar literatura não se trata simplesmente de ampliar o léxico e o conhecimento do mundo dos alunos, mas, também de acordar neles a ferramenta de reflexão sobre si, situando-os no nosso contexto latinoamericano, alertando-os a perceber que fomos criados em sociedades que foram colônias de nações europeias. A partir da literatura, o aluno poderá enxergar o outro e compreendêlo, ainda mais, poderá enxergar as próprias possibilidades de criação e de construção de si e da sua sociedade.

\section{O GÊNERO LITERÁRIO NA AULA: NONSENSE}

Muitas são as dúvidas com respeito a como abordar a literatura nas aulas, pois acredita-se que os métodos de ensino de literatura não são agradáveis para os alunos, sobretudo para os de ensino fundamental. A ludicidade em sala de aula de línguas, por outro lado, nem sempre toma em conta a possibilidade de utilizar a literatura. Apresentamos, portanto, a possibilidade de trabalhar com a literatura nonsense de modo a trazer um aporte que possa ajudar aos colegas a refletir como pode ser utilizada a literatura nas aulas de língua estrangeira. Estamos cientes do papel da escola e das exigências desta para com o papel do professor e apresentamos a ele práticas que possam colaborar para transformar o ensino de literatura em algo prazeroso e agradável dentro do contexto escolar. A seguir, algumas discussões teóricas que servem de base para a proposta.

O jogo, ao longo da história, tem sido muito importante para a humanidade, já que esse era o método de aprendizagem dos nossos antepassados (NEVADO FUENTES, 2008). Dessa forma, existem estudos que afirmam que o lúdico faz parte do processo de ensino/aprendizagem, mesmo sem ter sido considerado, inicialmente, pelos estudiosos como parte do processo educativo, tal como Nevado Fuentes (2008) aponta. A pesquisadora ainda mostra um resumido e ilustrativo panorama histórico composto desde filósofos como Platão e Aristóteles, e estudiosos como Juan Amós Comenio, Rousseau, Pestalozzi, até Huizinga, Vigotski, Piaget, entre outros como Leif e Ortega, etc.

Dentre os vários aportes, essa autora traz a reflexão que o autor Huizinga (apud NEVADO FUENTES, 2008, p. 4) desde o ponto de vista antropológico, o qual destacamos aqui, já que este pesquisador relaciona a cultura com o jogo da seguinte forma: "[...] la cultura no comienza como juego ni se origina del juego, sino que es, más bien juego. El fundamento antitético y agonal de la cultura se nos ofrece ya en el juego, que es más viejo que toda cultura."'. Já que a língua e a cultura estão intimamente relacionadas, a importância do jogo se faz evidente, portanto, na hora do aprendizado de uma língua estrangeira as atividades lúdicas são ações chave.

\footnotetext{
${ }^{4}$ Nossa tradução: [...] a cultura não começa como jogo nem se origina do jogo, mas que é, mas se bem é um jogo. O fundamento antitético e agonal da cultura nos é oferecido já no jogo que é mais velho do que toda cultura.
} 
A esse respeito, segundo o Diccionario de términos clave de ELE $E^{5}$ (2019), Kramsch (1983) observa que todo ser humano tem um mecanismo inato de aquisição linguística e que o filtro afetivo estaria presente em todos os alunos, consequentemente, o uso da ludicidade nas aulas se torna importante, pois permite que o filtro afetivo do aprendiz esteja baixo para que a entrada do input linguístico seja feita. Desta maneira, atividades lúdicas nas aulas de língua atuam como fatores que influem de maneira positiva o processo de aprendizagem das línguas. Nesse sentido,

Aunque el objetivo principal de los docentes de ELE no es el de hacer clases divertidas, si tenemos que tener en cuenta que el componente lúdico puede ser un fin para conseguir nuestro objetivo final, que no es otro que el aprendizaje y uso del español. De este modo, creando un ambiente positivo conseguiremos captar el interés de nuestros alumnos y el aprendizaje será mucho más efectivo ${ }^{6}$ (NEVADO FUENTES, 2008, p. 6)

Considerando os pressupostos anteriores, a literatura nonsense é o material mais do que indicado nas aulas de língua que permite que sejam trabalhadas essas inter-relações de língua, cultura, literatura e ludicidade. García de la Torre e Rábanos (2012) explicam que Nonsense traduzido literalmente significa "sem sentido", uma composição baseada em palavras inexistentes.

Segundo estes estudiosos,

En los textos escritos de este modo no importa lo que dicen las palabras sino la forma en que lo dicen, la cadencia y el ritmo. Es el idioma de muchas canciones, nanas y rimas infantiles, pero también el de textos de grandes escritores. La característica más distintiva es no tener sentido, ser decididamente absurdo.? (GARCÍA DE LA TORRE; RÁBANOS, 2012, p. 3).

O termo que leva este gênero literário provém da língua inglesa. No entanto, ainda que a primeira referência que se faça ao nonsense sejam as famosas nursery rbymes, e que o escritor inglês Edwar Lear, nascido no século XIX, escritor da época vitoriana, seja o

\footnotetext{
${ }^{5}$ Disponível em:

$<$ https://cvc.cervantes.es/ensenanza/biblioteca_ele/diccio_ele/diccionario/hipotesisfiltro.htm>. Acesso em: 15 set. 2019.

${ }^{6}$ Nossa tradução: [...] ainda que o objetivo principal dos docentes de ELE não é o de apresentar aulas divertidas, ainda assim temos que levar em conta que o componente lúdico pode ser um fim para conseguir nosso objetivo final, que não é outro que a aprendizagem e o uso do espanhol. Deste modo, criando um ambiente positivo conseguiremos captar o interesse de nossos alunos e a aprendizagem será muito mais efetiva.

${ }^{7}$ Nossa tradução: [...] nos textos escritos deste modo não importa o que dizem as palavras, mas, sim a forma com que se diz, a cadência e o ritmo. É esse o idioma de muitas canções, cantigas de ninar, e rimas infantis, mas, também, é a forma de muitos textos de grandes escritores. A característica mais distitiva é não ter sentido, ser decididamente absurdo.
} 
primeiro autor importante deste gênero, os pesquisadores García de la Torre e Rábanos (2012, p. 3) apontam que sua origem, tanto na língua inglesa quanto espanhola, se deu ao redor do século XVI, durante o período maneirista, das quais se tem vários textos nesse estilo que possam comprovar essa prática escrita, também, na península Ibérica. Portanto, podemos afirmar, que a sua escrita se estendeu pela Europa, até os nossos dias, a partir desse século. Outro famoso relacionado ao nonsense é o autor de Alice no país das maravilhas, Lewis Carrol. Contudo, as obras nonsense não se limitam a esses dois famosos escritores.

Como afirmam García de la Torre e Rábanos (2012), outras etapas muito produtivas foram os anos em que os -ismos imperaram na literatura: dadaísmo, cubismo, surrealismo, ultraismo, e vanguardas, etc. Assim, teríamos obras de Kafka que podem ser consideradas dentro desse gênero, por exemplo. De acordo com estes estudiosos, o nonsense pode ser achado em contos, lírica, obras orientadas para o público infantil (desde Lear): "con verdaderos valores artísticos y estéticos, rompiendo con los principios morales y facilitando al niño y niña que se entregue a la fantasia." (GARCÍA DE LA TORRE; RÁBANOS, 2012, p. 5).

Nosso objetivo nesse artigo não é de expor este gênero na sua totalidade. Devido a isso, recomendamos amplamente que sejam consultados Garcia de la Torre e Rábanos (2012) para maiores informações. Outrossim, estes pesquisadores mencionam um grupo de autores da língua espanhola que trabalharam esse gênero, dentre eles temos a: "Gloria Fuertes, Carmen Kurtz, Eliacer Cansino, Julio Cortázar, Eduardo Chicharro, Vicente Huidobro, María Elena Walsh, León de Greiff, Roald Dahl, Julián Ríos, Oliverio Girondo, Jorge Enrique Adoum, Guillermo Cabrera Infante, Fernando Alonso, Consuelo Armijo, [entre outros]" (GARCÍA DE LA TORRE; RÁBANOS, 2012, p. 5). Essa informação serve para entender a seleção de textos que apresentamos a seguir.

\section{UMA PROPOSTA LÚDICA DE LITERATUNA NA AULA DE ELE}

Vistas algumas das bases para a proposta didática, iniciamos, lembrando-nos de que as aulas estão propostas para serem desenvolvidas por meio de estratégias de ensino e mediações pedagógicas em que o aluno trabalhe ativa e reflexivamente o conteúdo programático abordado, relacionando-o a contextos sociais de vida. Adoptamos a proposta metodológica para o ensino de língua estrangeira por meio de práticas de leitura de literatura, cultura, intercultura de Antonio Mendoza Fillola (2008).

As sugestões propõem trabalhar em quatro encontros de uma hora aula no Ensino Fundamental I, podendo adaptar-se as abordagens dependendo da turma. Elegemos como objetos a música popular La gallina turuleca (1971), de Emilio Alberto Aragón Bermúdez, el Miliki ${ }^{9}$, La vaca estudiosa (1960), de María Elena Walsh e algumas ilustrações do livro do escritor inglês, Edward Lear, El libro de nonsense (1846). O objeto final considerado é uma curta seleção de alguns caligramas de autores hispano-falantes, tales

\footnotetext{
${ }^{8}$ Nossa tradução: [...] com verdadeiros valores artísticos e estéticos, rompendo com os princípios morais e facilitando ao menino e à menina que se entreguem à fantasia.

${ }_{9}^{9}$ Disponível em: <https:// diariocorreo.pe/miscelanea/fallece-miliki-creador-de-la-gallina-tur-212220/>. Acesso em: 20 ago. 2019.
} 
como Vicente Huidobro, Guillermo de Torre, Juan Larrea, Gerardo Diego na Espanha, Guillermo Cabrera Infante em Cuba, Oliverio Girondo, e inclusive do autor francês, Guilhaume Apollinaire, ou outros que possam estar disponíveis na internet.

Para trabalhar com o gênero literário proposto, em uma turma do fundamental, acreditamos que poderíamos, iniciar o primeiro módulo pela composição bem conhecida das crianças hispânicas, La gallina turuleca (1971), uma música popular, a modo de introduzir o nonsense. Será feita a apresentação da obra, com atividades de pré-leitura para acordar os conhecimentos empíricos e de mundo dos alunos. A seguir, a letra da música:

\author{
La Gallina Turuleca (Miliki) ${ }^{10}$ \\ Yo conozco una vecina, \\ que ha comprado una gallina, \\ que parece una sardina enlatada. \\ Tiene las patas de alambre, \\ porque pasa mucha hambre, \\ y la pobre está todita desplumada. \\ Pone huevos en la sala, \\ y también la cocina, \\ pero nunca los pone en el corral. \\ La gallina, turuleca, \\ es un caso singular, \\ la gallina, turuleca, \\ está loca de verdad. \\ Coro \\ La gallina turuleca, \\ ha puesto un huevo, \\ ha puesto dos, \\ ha puesto tres. \\ La gallina turuleca, \\ ha puesto cuatro, \\ ha puesto cinco, \\ ha puesto seis. \\ La gallina turuleca, \\ ha puesto siete, \\ ha puesto ocho, \\ ha puesto nueve. \\ ¿Dónde está esa gallinita? \\ Déjala, la pobrecita, \\ déjala que ponga diez.
}

Na sequência, daremos passo a leitura da letra da música, a modo de verificação de vocabulário e de outros sentidos que possam estar presentes no texto, com perguntas como: ¿qué entendieron? ¿Qué ocurre en ese texto? Será importante verificar o entendimento

${ }^{10}$ Disponível em: < https://www.letras.com/miliki/1376714/>. Acesso em: 20 ago. 2019. 
verso por verso, estrofe por estrofe, pois a tendência na sala de língua espanhola como língua estrangeira em turmas de alunos brasileiros é a de aceitar imediatamente os significados sem questionar o sem refletir sobre se realmente entenderam o que leram, já que existe uma proximidade entre as línguas.

Será feita a discussão sobre a letra da música, com questionamentos como atividades de prática da oralidade: ¿Qué les pareció la letra de esta música? ¿Las gallinas se comportan de esa manera? Em seguida, será feita a observação, leitura, audição etc., de maneira que depois possam ser feitas comparações entre o texto e o vídeo ${ }^{11}$ assistido. Após esta etapa, serão feitas questões que objetivam verificar como foi a recepção dos materiais (texto e vídeo), sendo, novamente, estimulada a oralidade na língua estrangeira.

Em seguida, aproveitando novamente o momento de audição da música, e do canto das crianças, poderá ser trabalhada a pronúncia dos fonemas da língua espanhola como as correspondentes aos dígrafos: $11, \mathrm{rr}$, ch e os sons das letras $\mathrm{j}, \mathrm{v}, \mathrm{b}$.

Como parte das atividades de integração de conhecimentos, o professor pode mencionar que o autor criou La gallina turuleca como parte do repertório de músicas de "Los payasos de la tele"12, que tinham um programa de televisão - El gran circo de TVE - na Espanha pelos anos 1970. Portanto, a letra da música foi pensada para ser engraçada e tornou-se muito famosa não somente na Espanha, mas também na América Latina, sendo que no Brasil foi conhecida nos anos 1980 quando Edgar Poças ${ }^{13}$ fez a adaptação para a língua portuguesa com o nome $A$ galinha magricela (1982) e foi gravada e divulgada pelo programa "A turma do Balão Mágico", muito popular até os dias de hoje.

Após essa etapa, refletir com os alunos sobre quais elementos deixam a música engraçada. A partir daí, podem ser trabalhados o uso dos adjetivos e de outras estruturas que tem a função de adjetivo, isto é, as orações subordinadas adjetivas. Como atividade unificada, pode ser feito um mapa mental com adjetivos, não dos normalmente utilizados, mas os "malucos", aqueles que são criativos, engraçados e até "fora da casinha", e, se desejar, a formação de algumas orações subordinadas adjetivas, como a palavra turuleca, ou a oração subordinada adjetiva: 'que parece una sardina enlatada', a modo de continuar com as características dos textos nonsense.

Logo após, seria feita, oralmente, a discussão da forma do gênero nonsense, a partir de perguntas feitas pelo professor, a modo de verificar se eles captaram a "presença" do "sem sentido" naquela obra. Se sobrarem alguns minutos, pedir para um voluntário iniciar uma narrativa inventada sob as formas nonsense, que poderá ser continuada pelos seus colegas.

No segundo encontro, o docente pode lembrar com a sala inteira o que foi feito na aula anterior, dando ênfase ao uso de adjetivos ou de orações subordinadas adjetivas e seu papel na hora da construção do texto como um todo e a forma final que dá à obra. Nesse dia, será introduzido, formalmente, o gênero nonsense ${ }^{14}$ e podem se dar exemplos que sejam

\footnotetext{
${ }^{11}$ Disponível em: <https://www.youtube.com/watch?v=XQaKFU3Fh_M>. Acesso em: 05 mar. 2019.

12 Disponível em: < https://www.taringa.net/+info/los-payasos-de-la-tele-gaby-fofo-miliki-yfofito_12pqci>. Acesso em: 05 mar. 2019.

${ }_{13}$ Disponível em: < http://www.edgardpocas.com.br/tag/cbs/>. Acesso em: 05 mar. 2019.

14 Mais informações, no texto de García de la Torre e Rábanos (2012), nas referências.
} 
do seu conhecimento. Para tal, podem ser levadas imagens do filme "Alice no país das maravilhas", "A fantástica fábrica de chocolate" e de "O gato da cartola", e outros títulos que possam ser do conhecimento deles. Também podem ser mencionadas as parlendas, como: O sapo não lava o pé e Borboletinha, para eles terem exemplos concretos do que o gênero nonsense pode oferecer.

O texto central a ser utilizado nessa aula será o poema conto popular, musicado, escrito pela argentina María Elena Walsh: La vaca estudiosa (1960), publicado como parte do livro de poemas: Tutú Marambá. É interessante mostrar pelo menos uma curta biografia da autora, pois ela é uma poeta, escritora, compositora, cantora e dramaturga muito importante da literatura infanto-juvenil latino-americana. Dessa vez, o título do conto será motivo para que os alunos possam predizer sobre o que pode acontecer nessa nova narrativa, entre outras perguntas pertinentes que ativem o conhecimento de mundo dos alunos. Passado esse momento, será entregue o texto impresso e a leitura dramatizada do conto será feita pelo professor.

\section{La vaca estudiosa (María Elena Walsh) ${ }^{15}$}

Había una vez una vaca en la Quebrada de Humahuaca. Como era muy vieja, muy vieja, estaba sorda de una oreja.

$\mathrm{Y}$ a pesar de que ya era abuela un día quiso ir a la escuela. Se puso unos zapatos rojos, guantes de tul y un par de anteojos.

La vio la maestra asustada y dijo: - Estás equivocada. Y la vaca le respondió: - ¿Por qué no puedo estudiar yo?

La vaca, vestida de blanco, se acomodó en el primer banco. Los chicos tirábamos tiza y nos moríamos de risa.

La gente se fue muy curiosa a ver a la vaca estudiosa. La gente llegaba en camiones, en bicicletas y en aviones.

Y como el bochinche aumentaba en la escuela nadie estudiaba.

${ }^{15}$ Retirado de: <http://www.silvitablanco.com.ar/mariaelenawalsh/mariaelenawalsh.htm>. Acesso em: 23 ago. 2019. 
La vaca, de pie en un rincón, rumiaba sola la lección.

Un día toditos los chicos se convirtieron en borricos.

$\mathrm{Y}$ en ese lugar de Humahuaca

la única sabia fue la vaca.

Feitas as estratégias de leitura de acordo ao estipulado por Solé (1998) - verificar se existe uma compreensão dos propósitos implícitos e explícitos da leitura; ativação dos conhecimentos prévios relevantes; orientar os alunos leitores para questões fundamentais do texto, em detrimento das triviais; avaliação com toda a sala de se o texto é compatível com o 'sentido comum': este texto tem sentido?; verificação constante mediante revisão e a recapitulação periódica da compreensão do texto; elaboração de inferências de diversos tipos ao longo do texto -. Igualmente, o texto oportuniza a prática da pronúncia dos sons da língua espanhola como as correspondentes aos dígrafos: 11 , rr, ch e os sons das letras $j, v, b$.

Como atividade, na sequência, poderá ser passado o vídeo do conto musicado e serão feitas comparações entre o texto lido, o que eles imaginaram ao ler e o vídeo (atividade de participação oral). Ao ouvir o estilo musical, o professor pode comentar com os alunos que Walsh compôs a música e que esta segue a tradição popular do interior da Argentina. O conto aparece localizado na 'Quebrada de Humahuaca', na província de Jujuy. Esse lugar é um vale que está no norte da Argentina, próximo da Bolívia, com montanhas coloridas - seria interessante levar ilustrações do lugar para os alunos terem uma referência -, e que esse estilo de música pertence a essa região, compartilhando da mesma tradição musical com Bolívia e Peru.

Outra atividade poderá ser feita ao identificar que tipo de adjetivos são utilizados na narrativa que fazem do texto um exemplo de narrativa nonsense. Em seguida, podem ser trabalhadas a formação de frases divertidas e 'sem sentido' com adjetivos - que podem ser previamente escolhidos e distribuídos pelo professor - ao estilo do nonsense, contando uma história maluca, sob o título da atividade: "historias chifladas". A aula será encerrada recolhendo os textos produzidos.

No encontro seguinte, partindo de uma imagem do livro de Edward Lear, sem o poema original, para iniciar um texto coletivo. Será proposta uma frase pelo professor que dê início ao texto coletivo. Na sequência, cada criança dará continuação à narrativa. Essa atividade é importante, pois já que se trata de uma atividade em grupo, os alunos podem ganhar confiança em escrever suas próprias histórias 'sem sentido'.

Em seguida, o professor pode distribuir outra imagem a cada aluno, também do livro de Edward Lear, sem o poema, muitas destas estão à disposição na internet, para dar início à atividade de escrita e de reescrita individual. No final da aula, serão lidos os poemas originais de Lear correspondentes aos desenhos utilizados na atividade. Se possível, antes de acabar o horário, serão lidas algumas composições dos alunos. Também, os alunos serão informados que os melhores textos finais serão expostos na escola. 
No último módulo, a turma será apresentada aos caligramas de Guilhaume Apollinaire, por ser o iniciador dessa modalidade, e a outras produções de este estilo escritas em língua espanhola. Será comentado brevemente como surgiram estes poemas cubistas e o sucesso que tiveram na época. Serão mencionados os autores mais importantes. Com o intuído de ilustrar esta modalidade de escrita, o professor levará cópias impressas ou vídeos da internet.

A atividade do dia é escrever um caligrama. Para isso, será feita uma pequena amostra de como fazer os caligramas (primeiro pensar no tema do texto, logo desenhar com lápis, para logo escrever ao longo do desenho os versos ou frases criadas pelos alunos. Para finalizar se retira o desenho). O professor pode mencionar que os alunos podem usar as mesmas ideias produzidas por eles em aulas anteriores, pero que deverá de ser melhorada, sempre sob a orientação e ajuda do docente. Esses textos também poderão ser expostos no mural da escola.

\section{CONSIDERAÇÕES FINAIS}

Depende de nós docentes mudar as velhas formas de abordar a literatura nas aulas de língua. Neste artigo tentamos, de alguma forma, mudar esse panorama. A proposta feita de abordagem à literatura com textos literários bem conhecidos, para a literatura infanto-juvenil universal e latino-americana visa a levar às aulas com literatura o desfrutar da leitura, além de trazer novas experiências para o professor no que diz respeito ao planejamento da aulas de língua com literatura. Como pode ser observado, as aulas propostas também permitem tratar do ensino da língua, porém não ser retira o seu valor ao texto literário.

A ludicidade também é um fator importante, pois ajuda a desmitificar a leitura literária, especialmente a ideia de que ela é enfadonha. Já o uso do gênero nonsense, acreditamos, oportuniza que o professor planeje aulas mais lúdicas, e a ver as novas possibilidades, além de perceber, também, o caráter polissémico da literatura. Isto, além das já mencionados benefícios, fará com que possa ofertar aulas mais significativas para seus alunos.

É imprescindível que o ensino/aprendizagem de línguas seja sempre realizado com materiais e situações contextualizados e, como aqui mostramos, os textos literários são excelentes formas de fazer isso por meio de uma situação real de uso da língua estrangeira, com toda a expressividade que ela tem no seu ambiente primário de uso.

\section{REFERÊNCIAS}

ABREU, M. Cultura letrada: literatura e leitura. São Paulo: Editora UNESP, 2006.

CANDIDO, A. O direito à literatura. Vários escritos. 4. ed. reorg. pelo autor. São Paulo: Duas Cidades, 2004. 
EAGLETON, T. Teoria da literatura: uma introdução. Tradução de Waltensir Dutra. São Paulo: Martins Fontes, 2003.

FLECK, G. F.; ZUCKI, R. Letramento literário: práticas de leitura do texto literário nos anos iniciais do ensino fundamental. Grau Zero: revista de crítica cultural. Alagoinhas, v. 3, n. 2, p. 141-159, 2015. Disponível em: < https://www.revistas.uneb.br/index.php/grauzero/article/view/3312/2180 >. Acesso em: 17 out. 2019.

FLECK, G. F. Tópicos de cultura en la enseñanza/aprendizaje de una lengua extranjera: caminhos para la descolonización en América Latina. In: FIUZA, A. A. de F. A formação de professores de espanhol no âmbito do PARFOR: teorias, práticas e aprendizagens. Cascavel: UNIOESTE, pp. 19-92, 2015.

FREIRE, P. A importância de ler: em três artigos que se completam. Coleção Polêmicas do nosso tempo; 4. 23.ed. São Paulo: Cortez, 1989.

FREIRE, P. Pedagogia do oprimido. 17ª ed. Rio de Janeiro: Paz e Terra, 1987.

GARCÍA DE LA TORRE, M.; RÁBANOS, C. de M. Nonsense: literatura infantil 2012. (s.l.). Disponível em: <https://vdocuments.mx/trabajo-nonsense.html>. Acesso em: 23 fev. 2019.

JOUVE, V. Ensinar literatura. In: JOUVE, V. Por que estudar literatura? Tradução de Marcos Bagno e Marcos Marciolino. São Paulo: Parábola, pp. 113-162, 2012.

MENDOZA FILLOLA, A. La utilización de los materiales literarios en la enseñanza de lenguas extranjeras. Alicante: Biblioteca Virtual Cervantes, 2008. Disponível em: < http://www.cervantesvirtual.com/obra-visor/literatura-cultura-intercultura-reflexionesdidacticas-para-la-ensenanza-de-espanol-lengua-extranjera--0/html/a41b0aab-b5504929-b9af-facfee4bc019_2.html>. Acesso em: 18 set. 2019.

NEVADO FUENTES, C. El componente lúdico en las clases de ELE. MarcoELE. Revista de didáctica ELE. n. 7, pp. 14, 2008. Disponível em: <https://marcoele.com/descargas/7/nevado_juego.pdf>. Acesso em: 18 ago. 2018.

SANTIAGO, S. Uma literatura nos trópicos. 2. ed. Rio de Janeiro: Rocco, 2000.

SANZ PASTOR, M. El lugar de la literatura en la enseñanza del español: perspectivas y propuestas. Anuario del Instituto Cervantes, 2006-2007. Disponível em: < https://cvc.cervantes.es/lengua/anuario/anuario_06-07/pdf/ele_01.pdf >. Acesso em: 10 jun. 2018.

SOLÉ, Isabel. Estratégias de leitura. Porto Alegre: Artes Médicas, 1998.

WILLIAMS, Raymond. Marxismo e literatura. Tradução de Waltensir Dutra. Rio de Janeiro: Zahar Editores, 1979. 